S. Chow*, D.H. Yates ${ }^{*}$ and P.S. Thomas ${ }^{*}$ ?

*Dept of Pathology, School of Medical Sciences, Faculty of Medicine, University of New South Wales, "Dept of Thoracic Medicine, St Vincent's Hospital and Research and Education Unit, Workers' Compensation (Dust Diseases) Board, and "Dept of Respiratory Medicine, Prince of Wales Hospital, Randwick, Sydney, Australia.

\section{STATEMENT OF INTEREST}

None declared.

\section{REFERENCES}

1 Rosias PP, Jobsis Q, van de Kant K, et al. Global condensation: a "climate change" towards better standardisation of exhaled breath condensate measurements. Eur Respir J 2008; 31: 684-685.

2 Liu J, Conrad DH, Chow S, Tran VH, Yates DH, Thomas PS Collection devices influence the constituents of exhaled breath condensate. Eur Respir J 2007; 30: 807-808.

3 Prieto L, Ferrer A, Palop J, Domenech J, Llusar R, Rojas R. Differences in exhaled breath condensate $\mathrm{pH}$ measurements between samples obtained with two commercial devices. Respir Med 2007; 101: 1715-1720.

4 Rosias PP, Robroeks CM, Niemarkt HJ, et al. Breath condenser coatings affect measurement of biomarkers in exhaled breath condensate. Eur Respir J 2006; 28: 1036-1041.

DOI: $10.1183 / 09031936.00085408$

\title{
Exhaled breath condensate is not suitable to detect EGFR somatic mutations
}

\section{To the Editors:}

Somatic mutations in the tyrosine kinase domain of the epidermal growth factor receptor (EGFR) are molecular targets of great clinical interest in lung cancer. In particular, its ability to permit clinical efficacy of specific therapies with tyrosine kinase inhibitors (i.e. gefitinib or erlotinib) has been stressed [1, 2].

Interestingly, our group has already shown that the exhaled breath condensate (EBC) can be a useful and noninvasive way to collect biological samples derived from high up and deep within the airways $[3,4]$. EBC has been demonstrated to be informative on molecular alterations of nonsmall cell lung cancer (NSCLC) and to characterise the oxidative and inflammatory process in the airways/lung $[5,6]$. In particular, we recently demonstrated an overlapping microsatellite signature from EBC and tumour tissue of the same patient showing that it already contained genetic markers potentially useful for early lung cancer diagnosis [4].

Our aim was to verify the possibility to research EGFR mutations in EBC and, therefore, to use them again as a noninvasive diagnostic tool for lung cancer. For this reason, 23 patients with histological evidence of NSCLC were enrolled in the study. As several reports have shown that the most frequent mutations are in-frame deletions in exon 19, point mutation in exon 21 (L858R) or amino acid substitution in exon 20 (T790M) which are implicated in the tyrosine kinase inhibitors sensitivity [2], exons 18-21 of EGFR were sequenced on DNA extracted from paraffin tissues of all cases and from EBC of 10 patients.

EGFR mutations in tumour tissues were analysed first. Only one patient presented with a pathological deletion in exon 19, a) C C C GT C GC TA T CAA $\frac{170}{180}$ G A T TAA GAG A A GC A A

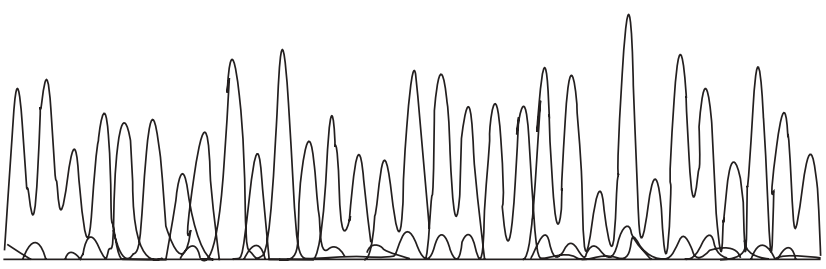

b)
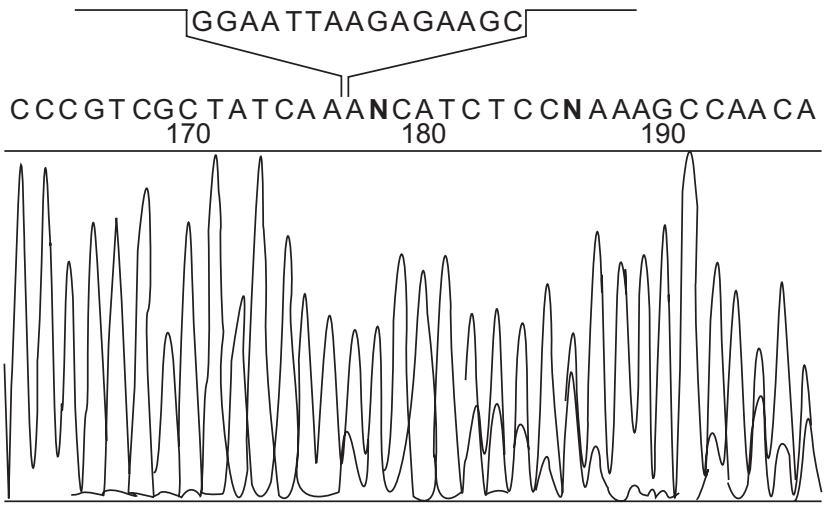

FIGURE 1. Sequencing of epidermal growth factor receptor exon 19 in DNA from a) exhaled breath condensate and b) tumour tissue of the same patient. The pathological deletion 745_750del is clearly evident in the tissue but not in the exhaled breath condensate. 


\begin{tabular}{|c|c|c|c|}
\hline TABLE 1 & $\begin{array}{l}\text { Patients characteristi } \\
\text { cell lung carcinoma }\end{array}$ & idermal gro & receptor alterations in 23 patients affected by nonsmall \\
\hline Alterations & Patients n & Age yrs & Histotype \\
\hline 745_750del & 1 & 76 & Other histotype \\
\hline rs17337100 & 3 & $72(57-78)$ & Adenocarcinoma $(n=1)$, other histotype $(n=2)$ \\
\hline rs2017000 & 4 & $69.5(58-72)$ & Adenocarcinoma $(n=2)$, other histotype $(n=2)$ \\
\hline rs1050171 & 21 & $68(53-82)$ & Squamous carcinoma $(n=3)$, adenocarcinoma $(n=8)$, other histotype $(n=10)$ \\
\hline rs17337135 & 2 & $67.5(57-78)$ & Adenocarcinoma $(n=1)$, other histotype $(n=1)$ \\
\hline
\end{tabular}

745_750del (4.3\%; fig. 1). Several polymorphisms were present in the entire analysed region in 21 patients. Most of the polymorphisms were in the intron regions: rs17337100 IVS17104 C $>$ A $(n=3) ; r s 2017000$ IVS19+96A $>$ G $(n=6) ; r s 10241451$ IVS19-60T $>C(n=7)$; and one synonymous in exon 20: rs1050171 G787A ( $n=21$; table 1). With regards to the EBC analyses, we validated the possibility of using untreated EBC for mutation detection, as reported in the only previous study which investigated gene mutation in DNA from EBC [7]. By applying PCR protocol on untreated EBC we were unable to obtain sufficient amounts of clean amplicons. We then used purified DNA to sequence. EBC-DNA was investigated in the patient who presented with the pathological mutation and in nine other patients carrying polymorphisms in introns 19 and 20 and in exon 20. No alterations have been evidenced by sequencing these sites (fig. 1).

The same 10 patients have also been investigated for microsatellite instability and loss of heterozygosity in the five loci that have been identified in previous studies $[3,4]$. The five polymorphic microsatellite markers from chromosome $3 p$ account for hot spots of deletions in lung cancer and are believed to be involved in lung carcinogenesis. The analysis conducted in the EBC-DNA and the tumour tissue DNA confirmed our previous finding of identical microsatellite alterations in the two biological sites [4].

These results suggest that the cellular components present in EBC are possibly not representative of the tumour. The evidence that microsatellite alterations can occur in EBCDNA, such as in tumour tissue DNA compared with EGFR somatic mutations, could depend on two main reasons. First of all, microsatellite alterations are much more frequent and depend on variations in a fragment of DNA some bases long, whereas EGFR mutations occur at a lower frequency and affect one or very few nucleotides. Secondly, microsatellite alterations could depend on the action of predisposing factors (i.e. alcohol, smoking, etc.) on oral mucosa more than on tumourdependent somatic alterations.

In conclusion exhaled breath condensate cannot be used to investigate somatic alterations of epithelial growth factor receptor. However, it is a suitable sample to detect susceptibility markers for lung cancer risk.

\section{A. Paradiso* ${ }^{*}$, S. Tommasi $*$, R. Pinto*, G.E. Carpagnano ${ }^{\#}$ and M.P. Foschino-Barbaro"}

*Clinical Experimental Oncology Laboratory, National Cancer Institute, Bari, "Institute of Respiratory Disease, University of Foggia, Foggia, Italy, and "Authors contributed equally to the work.

\section{STATEMENT OF INTEREST}

None declared.

\section{REFERENCES}

1 Lynch TJ, Bell DW, Sordella R, et al. Activating mutations in the epidermal growth factor receptor underlying responsiveness of non-small-cell lung cancer to gefitinib. N Engl J Med 2004; 50: 2129-2139.

2 Pao W, Miller V, Zakowski M, et al. EGF receptor gene mutations are common in lung cancer from "never smokers" and are associated with sensitivity of tumors to gefitinib and erlotinib. Proc Natl Acad Sci USA 2004; 101: 13306-13311.

3 Carpagnano GE, Foschino-Barbaro MP, Mulè G, et al. 3p microsatellite alterations in exhaled breath condensate from patients with non-small cell lung cancer. Am J Respir Crit Care Med 2005; 172: 738-744.

4 Carpagnano GE, Foschino-Barbaro MP, Spanevello A, et al. Overlapping of $3 p$ microsatellite signature in DNA from EBC and tumor tissue in patients with NSCLC. Am J Respir Crit Care Med 2008; 177: 337-341.

5 Carpagnano GE, Foschino-Barbaro MP, Resta O, Gramiccioni E, Carpagnano F. Endothelin-1 is increased in the breath condensate of patients with non-small cell lung cancer. Oncology 2004; 66: 180-184.

6 Gessner C, Scheibe R, Wotzel M, et al. Exhaled breath condensate cytokine patterns in chronic obstructive pulmonary disease. Respir Med 2005; 99: 1229-1240.

7 Gessner C, Kuhn H, Toepfer K, Hammerschmidt S, Schauer J, Wirtz H. Detection of p53 gene mutations in exhaled breath condensate of non-small cell lung cancer patients. Lung Cancer 2004; 43: 215-222. 